\title{
A PRATICA DA EDUCAÇÃO EM SERVIÇO EM UMA INSTITUIÇÃO PRIVADA
}

\author{
Maria Itayara C.S. Padilha*
}

PADILHA, M.I.C.S. A prática da educação em serviço em uma instituição privada. Rev. Esc. Enf. USP, v. 25, n. 1, p. 3-16, abr. 1991.

Expcriência realizada em hospital particular, no Rio de Janeiro, com 60 leitos, no periodo de 1987-1988. Os objetivos do trabalho são: - relatar a experiência de coordenar a educaçāo em serviço em uma instituiçáao privada; - contribuir para o enriquecimento técnico-científico da enfermagem brasileira. $A$ educação em serviço ocorreu nas seguintes áreas: 1) Seleção de pessoal; 2) Treinamento; 3) Reciclagem $e$ educação continuada; 4) Reuniões de grupo de estudos; 5) Aperfeiçoamento, aprimoramento, desenvolvimento do grupo através do estimulo a participação ativa em eventos de enfermagem.

UNITERMOS: Educação continuada em enfermagem. Educaçũo cm serviço.

\section{I) INTRODUÇĀO}

A educação é essencialmente uma atividade humana de comunicação. Sendo um ser social, o Homem comunica-se, com fato relaciona-se. A educação significa todos os processos pelos quais o homem adquire compreensão do mundo, bem como aptidão para lidar com seus problemas. A educação visa a formação do ser global e sua integração no meio social ao qual se destina (VIEIRA et al, 1980).

Levando-se em conta a necessidade constante de melhoria de qualidade e aperfeiçoamento do pessoal, as empresas têm-se voltado para a educação, como parte do trabalho.

A "educação em serviço" é fundamental para uma tomada de consciência da necessidade de formação profissional sistemática, programada de modo a atingir todos os níveis de pessoal, oferecendo a todos oportunidade de crescimento profissional e pessoal.

Conforme SANTOS et al. (1984), a "educação em serviço é um processo contínuo e planejado que visa de acordo com os interesses e objetivos da instituição, promover o desenvolvimento de seu pessoal através de programas e planos educativos, a fim de propiciar ao homem ascensão individual e profissional, e prover a instituição de pessoal

\footnotetext{
- Professora Assistente do Departamento de Metodologia da Escola de Enfermagem Anna Nery - Universidade Federal do Rio de Janeiro. Mestre em Administração Aplicada à Enfermagem.
} 
qualificado, satisfeito e estável". Corroborando esta afirmação, KRON (1989) assevera que a educação em serviço é uma atividade contínua, cujas etapas são de planejamento, execução, coordenação, ensino, supervisão e avaliação, sendo, estas duas últimas, os principais fatores no controle dos resultados.

O enfermeiro é um educador em qualquer campo de atuação, seja no ensino ou em serviço, e tal função é tão importante quanto a assistencial, administrativa ou científica, pois estas, sem a educação, deixam de ter significado. Portanto, a formação universitária é fundamental para que o enfermeiro adquira uma visão educativa do seu trabalho perante a equipe, pacientes, familiares e comunidade.

De acordo com DU GAS (1978), o beneficiário da educação em serviço, bem feita, será, além da equipe de enfermagem que estará melhor capacitada, o paciente que receberá cuidados de melhor qualidade, terá orientações mais corretas a respeito de sua doença e dos cuidados consigo mesmo; com isto poderá reduzir o tempo de permanência no hospital e evitará reinternações freqüentes, podendo o paciente ser encaminhado apenas ao ambulatório para orientações posteriores.

O presente trabalho abordará uma experiência de educação em serviço vivenciada pela autora em uma instituição privada, realizada por dois anos quando coordenou a educação em serviço na instituição (1987-1988) e procurou contribuir para o enriquecimento técnico-científico da equipe de enfermagem através de novos conhecimentos, desenvolvimento de potencialidade e ajustamento de novos funcionários.

Os objetivos deste trabalho são:

- Relatar a experiência de coordenar a educação em serviço em uma instituição privada;

- Contribuir para o enriquecimento técnico-científico da enfermagem brasileira.

\section{II) DESENVOLVIMENTO}

O trabalho foi desenvolvido em instituição privada, na cidade do Rio de Janeiro, mantida apenas pela clientela que atende. Possui 54 leitos náo divididos por especialistas e 6 leitos de CTI, num total de 60 leitos. O corpo clínico é aberto, o que dificulta a instituição de rotinas, como por exemplo: preparo pré-operatório, curativos, etc.

Possui um serviço de enfermagem organizado, sendo a equipe composta de: Enfermeiras, Auxiliares de Enfermagem e Secretária de Enfermagem. A rotatividade de pessoal é grande, devido principalmente à ocorrência de concurso para us serviços públicos. A necessidade de segurança e melhores salários, induz as pessoas a optarem por estes últimos. 
A educação em serviço è subordinada diretamente à Diretora do Serviço de Enfermagem, tendo este total autonomia de decisão. LEITE (1988) assegura que, para a efetividade dos programas, a educação em serviço deve reportar-se administrativa e tecnicamente ao Serviço de Enfermagem, que, inclusive, deve ser responsável pela coordenação e ter autonomia na tomada de decisões.

Em abril de 1986, com a mudança de chefia de enfermagem da instituição, e organização do Serviço de Enfermagem, aumento do quadro de pessoal. filosofia de trabalho voltada para o crescimento profissional e melhoria da qualidade de assistência prestada à clientela, foi criado o programa de educação em serviço.

Com o aumento do quadro de pessoal de enfermagem como um todo, os objetivos iniciais foram:

- Selecionar e treinar Enfermeiras, Auxiliares de Enfermagem e Secretárias de Enfermagem, preparando-os para assumir as atividades inerentes a cada um, a fim de possibilitar a esse pessoal, o exercício de uma assistência de enfermagem de qualidade;

- Atender aos interesses da instituição, através de uma filosofia educativa que conduza os funcionários a alcançarem os resultados desejados.

Com o relativo equilíbrio de pessoal, partiu-se para o alcance dos objetivos, através da ampliação das áreas de atuação em serviço, passando-se então a realizar programas de reciclagem, a fim de ser padronizada a execução de técnicas, incentivar a educação continuada, a atualização e o crescimento técnico-científico dos funcionários.

$E$ educação em serviço abrangeu quatro áreas de atuação:

- Seleção de Pessoal

- Treinamento

- Reciclagem e Educação Continuada

- Reuniões de Grupo de Estudo

\section{1 - Seleção de Pessoal:}

A Seleção de Pessoal de Enfermagem é realizada a partir do momento em que haja necessidade de preencher vagas do quadro fixo da instituição.

Nesta área existe necessidade de haver uma integração entre o setor de educação em serviço e o departamento de pessoal, já que os candidatos preenchem ficha de inscrição e são contactados através do mesmo. Desta ficha constam dados pessoais e profissionais do candidato, sendo utilizada para seleção inicial. A partir daí, o candidato é chamado para uma prova escrita, subjetiva, com finalidade de ser feito o diagnóstico da competência do mesmo. A média de classificação exigida é 7,0 (sete) para Enfermeiros, 5,0 (cinco) para Auxiliares de Enfermagem e 5,0 (cinco) para Secretárias de Enfermagem. 
Os aprovados são chamados para uma entrevista que segue o roteiro contido no Anexo I, onde são pedidas informações mais detalhodas sobre a experiencia profissional do candidato, caracteristicas cognitivas, afetivas e psicomotoras, bem como sobre sua disponibilidade.

Os candidatos são chamados para admissão de acordo com $\cap$ resıltado de sua prova e entrevista e sua disponibilidade.

2 - Treinamento:

O tempo de duração do treinamento é de um mês, ficando totalmente disponivel para o mesmo neste periodo. De acordo com TORRES (1986), é importante o treinamento para o recém-admitido, mesmo havendo pressões para o imediato aproveitamento do recém-ingressado, como ocorre em inúmeras instituições.

O treinamento é composto de quatro passos:

2.1 - Introdução ao trabalho

2.2 - Aulas teóricas

2.3 - Prá icica Supervisionada

2.4 - Avaliação

\section{1 - Introdução ao trabalho}

Com a finalidade de integrar o novo funcionário à instituição e facilitar a sua adaptação, o mesmo é orientado sobre a estrutura administrativa e organizacional da instituição em geral e do Serviço de Enfermagem em particular, normas e rotinas dos mesmos, suas funções e ética profissional. O funcionário é orientado também sobre o processo de treinamento, para que se inteire do que será esperado dele em termos de produtividade. A seguir é feita uma visita à instituição, para conhecimento do local e início da sua integração à equipe.

Durante este passo inicial, são tiradas as dúvidas do funcionário sobre as informações prestadas, bem como ressaltada a importância do trabalho que irá desempenhar, de modo a valorizá-lo e estimulá-lo para seu crescimento contínuo.

\section{2 - Aulas teóricas em sala de aula}

São estas ministradas tanto para Enfermeiros como para Auxiliares de Enfermagem, diferindo, naturalmente, no conteúdo. Para os Auxiliares, procura-se dar ênfase às técnicas básicas de enfermagem, de acordo com a rotina da instituição, tais como: medida dos sinais vitais, higiene, aspiração traqueal, PVC, etc. Para as Enfermeiras, são discutidas as funçōes do Enfermeiro, o processo de enfermagem, princípios de quimioterapia, hiperalimentação parenteral, etc. Normalmente as aulas são de duas horas, diariamente, durante todo o treinamento.

\section{3 - Prática Supervisionada}

Como a instituição não é dividida por especialidades, o funcionário é colocado para treinar com um grupo fixo de trabalho, sob a supervi- 
são direta da Enfermeira encarregada do andar e indireta da responsável pela Educação em Serviço. Procura-se fazer da enfermeira uma participante direta do treinamento, de forma que esta se mantenha constantemente atualizada e consciente de seu papel profissional, já que o Enfermeiro é um educador em qualquer campo que atue. A prática sofre algumas dificuldades, devido ao tipo de clientela que se interna na instituição, que por ser de nível sócio-econômico elevado e estar "pagando", nem sempre permite que o novo funcionário execute cuidadados de enfermagem.

$\mathrm{Na}$ medida em que as técnicas são dadas na teoria, o treinando as vai executando na prática, sendo este aprendizado gradativo. forma:

Para as Enfermeiras a prática supervisionada ocorre da seguinte

- 14 Semana: Adaptação. Tomar conhecimento do andar, inclusive de rotinas, impressos, materiais e execução de técnicas de modo geral.

. 2 Semana: Assumir cuidados integrais de um ou dois pacientes, e elaborar o plano de cuidados para os mesmos, bem como anotar no prontuário a evolução do seu estado. Pode também, durante esta semana, executar outras atividades que deseje, desde que consiga conciliá-las com as tarefas designadas.

- $3^{*}$ e $4^{*}$ Semanas: Exercitar liderança. Inicialmente, a Enfermeira do andar divide o mesmo com a treinanda para delimitar a área de atuação de cada um, de forma que esta as vá assumindo gradativamente, para que, no final, a Enfermeira do andar apenas fique dancio cobertura à colega.

\section{4 - Avaliação}

Ao término do mês de treinamento, os responsáveis pela "educação em serviço" fazem avaliação do treinamento, de acordo com modelo estabelecido (Anexos II e III), onde são avaliados os pontos fortes e fracos do seu desempenho, individualmente, tendo o Enfermeiro do andar, participado na avaliação do mesmo. A avaliação da Enfermeira aborda aspectos referentes a liderança, participação, conhecimento e atuação do avaliado e descreve seu perfil. A do Auxiliar de Enfermagem refere-se a integridade moral, disciplina, equilibrio emocional, liderança, iniciativa, saúde, qualidade do trabalho, facilidade para aprender, aparência pessoal e hábitos de segurança.

$\mathrm{Na}$ verdade, utiliza-se também a "avaliação formativa", através da supervisão e orientação diárias de acordo com o planejamento estabelecido (CARVALHO, 1979, TURRA, 1975). Após a avaliação final o funcionário assume a vaga correspondente a sua contratação.

\section{3 - Reciclagem e Educação Continuada:}

A "educação continuada" é realizada no dia a dia, por todas as Enfermeiras da Instituição, havendo também a liberação do funcionário para cursos, encontros e etc. A fim que este ocorra, é necessário 
que a filosofia do serviço de enfermagem esteja voltada para o crescimento individual e profissional da equipe.

A reciclagem é realizada concomitante à atualização do Manual de Normas e Procedimentos, tendo o grupo sido inicialmente preparado para participar da mesma.

A técnica é elaborada de acordo com a literatura, adequando a realidade local, e é encaminhada aos andares para execução. A Enfermeira supervisiona a execução da mesma pelo Auxiliar de Enfermagem, avaliando-o e orientando-o se houver necessidade. O grupo analisa e critica a técnica sugerindo alterações que julgue necessárias, e ela retorne para a avaliação da responsável pela Educação em Serviço. Cada técnica tem um tempo mínimo de uma semana para execução. Ao término da avaliação, a mesma é colocada no Manual de Normas e Procedimentos.

4 - Reuniões de Grupo de Estucios:

São feitas reuniões semanais, com a participação de Enfermeiras e Auxiliares de Enfermagem. Nestas ocasiões, algum dos membros da equipe de saúde apresenta um tema de interesse do grupo de enfermagem.

Ao fim de cada ano é feita a avaliação das reuniões e o grupo apresenta suas críticas e sugestões, bem como, sugere temas de interesse para o ano seguinte. Tais reuniōes visam atualizar a equipe, levando em conta as necessidades levantadas, a fim de que a qualidade de assistência de enfermagem seja constantemente aprimorada.

Conforme os dados levantados pelo Conselho Federal de Enfermagem - COFEn (1985), verifica-se que os meios utilizados pelo pessoal de enfermagem para sua atualização foram: livros e periódicos, e treinamento em serviço, para técnicos e auxiliares. Ainda relatando sobre as dificuldades encontradas para atualização desse pessoal, estão em primeiro lugar "os problemas econômicos e, em segundo, a deficiência das instituições onde trabalham: falta de programas de treinamento em serviço e falta de estimulo para se atualizarem".

\section{5 - Aperfeiçoamento, Aprimoramento e/ou Desenvolvimento:}

Este aspecto da educação em serviço enfoca o desenvolvimento do profissional em termos de aumentar a qualidade e responsabilidade do pessoal, investindo em cursos, congressos, pós-graduação; assim, os profissionais terão condições de aumentar a qualidade dos serviços prestados na instituição. Neste ponto, é necessária a participação do Serviço de Enfermagem, já que a autorização para a saída do funcionário parte daí. A liberação deve ser concedida como prêmio, sem exigir que o funcionário reponha as horas que esteve ausente, para o seu engrandecimento e o da empresa.

$\mathrm{Na}$ instituição em questão, quando havia algum tipo de evento de enfermagem era feito "sorteio" dos membros da equipe que iriam participar do mesmo, e estes eram liberados completamente. 
Os benefícios a serem atingidos pela Educação em Serviço são:

Para o funcionário:

- facilita o ajustamento do novo funcionário;

- propicia novos conhecimentos;

- melhora o desenvolvimento técnico;

- influencia na mudança de comportamento;

- dá maior segurança e valorização;

- reduz os acidentes de trabalho.

Para o paciente/comunidade:

- melhora a qualidade de assistência recebida;

- aumenta a confiança no trabalho de equipe;

- reduz o tempo de permanência de hospitalização.

Para a empresa:

- maior procura do hospital por parte do público;

- maior credibilidade do público no hospital;

- melhor qualidade do atendimento prestado aos pacientes;

- redução dos custos.

\section{III) CONCLUSÃO}

MARX; SECAF (1985) dizem que a qualidade de assistência de enfermagem que atende as necessidades do paciente, prestada por uma equipe treinada e competente, faz crescer o conceito da instituição hospitalar junto ao público, o que foi obtido por meio da educação formal. Assim, novos pacientes são internados atraídos pela qualidade de assistência prestada naquele nosocômio.

As instituições privadas visam lucro e consequientemente a maioria dos diretores que as compõem acreditam que devem reduzir custos não contratando pessoal qualificado para a prestação da assistência de enfermagem. Consideramos isto um grande engano, já que quanto melhor a equipe, mais a população ficará satisfeita com a assistência recebida, o. que contribui indiretamente para o aumento de lucro da mesma.

Felizmente, aos poucos este modo de pensar está sendo substituido por uma visão mais ampla do papel da enfermagem na assistência ao paciente, que resulta assim em melhor condição de trabalho para o pessoal e no aperfeiçoamento da equipe obtido por meio da educação em serviço.

Acredita-se que este processo de mudança seja lento porém evolutivo, de forma a que o Enfermeiro conquiste mais este espaço de atuação. Vale a pena refletir sobre os porquês disto não ter acontecido há mais tempo. Será que as enfermeiras realmente têm demonstrado que são imprescindíveis no processo ensino/aprendizagem institucional? Será que elaboraram e realizaram programas de educação em serviço coerentes com a necessidade da equipe, ou com as suas próprias?

NEVES (1981) esclarece estas dúvidas afirmando: "o que pode dificultar o processo da educação em serviço é não se ter um grupo de 
profissionais capacitados para esta função, fazendo um trabalho descontínuo e sem planejamento".

A eảucação em serviço favoreceu a capacitação da equipe, com conseqüente melhora na qualidade da assistência de enfermagem; maior procura da clientela pela instituição e; redução de custos institucionais.

Para finalizar, é opinião da Autora que a educação em serviço não funciona se não houver o envolvimento participativo de toda equipe no processo, demonstrando o quanto é importante o trabalho e o comprometimento conjunto, na obtenção dos resultados esperados.

PADILHA, M.I.C.S. The experience of the service education in a private hospital. Rev. Esc. Enf. USP, v. 25, n. 1, p. 3-16, apr. 1991.

The experience was developed in a private hospital of the Rio de Janeiro, with 60 patients, in the period of 1987 to 1988 . The objective are: To report the experience of the service education cordenation in a private institution. To contributer to the practice and scientific improvement of the brazilian nursing. The service education happened in the following areas: 1) Personnel recruitment; 2) Training; 3) Recycling and continuous education; 4) Case study; 5) Improvement and development through the incentive in talking part of nursing meetings.

UNITERMS: Education nursing continuing. Nursing education.

\section{REFERENCIAS BIBLIOGRAFICAS}

CARVALHO V.L. Ensino de enfermagem e metodologia. 2. ed. Rio de Janeiro. Cultura Médica, 1979.

CONSELHO FEDERAL DE ENFERMAGEM. O exercicio da enfermagem nas instituiçõen de saúde do Brasil 1982/1983: a força de trabalho na enfermagen. Rio de Janeiro, Associação Brasileira de Enfermagem, 1985. V.1.

DUGAS, B.W. Enfermagem prática. 3. ed. Rio de Janeiro, Interamericana, 1978.

KRON, T. Manual de enfermagem. 5. ed. Rio de Janeiro, Interamericana, 1989.

LEITE, M.M.J. Estudo sobre programas de preparo da equipe de enfermagem: fases implementadas nos hospitais campo de prática da Escola de Énfermagem da Universidade de São Paulo. Rev. Esc. Enf. USP v. 22, n. 2, p. 189-98, 1988.

MARX, L.C.; SECAF, V. Enfermeira: segurança para o paciente, investimento para o hospital. Rev. Paul. Enf., v. 5, n. 2, p. 65-7, 1985.

NEves, S.T. Educação em saúde no hospital. Rev. Paul. Hosp., v. 5, n. 8, p. 227-33, 1981.

SANTOS, B.M.O. et al. Proposta de um perfil do enfermeiro. Rev. Paul. Enf. v. 4, p. 132-4, 1984.

TORRes, M.N.F.B. Saúde Pública: formação de recursos humanos na área da saúde. Săo Paulo, Centro Cultural Brasileiro, 1986. mimeografado.

TURRA, C.M.G. et al. Planejamento de ensino e avaliacão. 10. ed. Porto Alegre, Sagra, 1975.

VIEIRA, I.I. et al. A competência continuada e a assistência de enfermagem. IN: CONGRESSO BRASILEIRO DE ENFERMAGEM, 32., Brasilia, 1980 Anais. Brasilia, Associação Brasileira de Enfermagem, 1980. p. 47-56. 


\section{ANEXO I}

FICHA DE ENTREVISTA

Nome:

Data:

Experiência anterior: locais de trabalho; tempo de permanência; motivo da saída; setores de trabalho:

- Experiência técnica: Habilidades

- Quais técnicas sabe executar?

- Segurança:

- Iniciativa:

- Agilidade:

- Conhecimento científico *:

- Planos de cuidado*:

- Facilidade para aprender:

- Relacionamento de grupo: subordinados / iguais /superiores:

- Liderança: tomada de decisão / avaliação:

- Responsabilidade:

- Organização: planejamento / coordenação:

- Aceitação de críticas:

- Assiduidade e pontualidade:

- Aparencia:

- Impressão:

- Disponibilidade:

( ) SD par ( ) SD ímpar ( ) SN par ( ) SN ímpar ( ) Total

* Perguntas apenas para Enfermeiras. 


\section{ANEXO II \\ BOLETTM DE AVALTAÇAO}

Auxiliares de Enfermagem

\section{OBJETIVOS:}

1) Controlar a eficiência do pessoal, fornecendo critérios para efetivaçåo, transferência, demissão.

2) Dar à Chefia a base necessária para informar ao funcionário o seu desempenho profissional.

3) Diagnosticar as causas do desempenho insatisfatório e estabelecer as condições de melhoria e aperfeiçoamento.

4) Estimular o potencial de cada individuo.

5) Melhorar as relações humanas no trabalho.

\section{COMO UTILIZAR O BOLETTM DE AVALIAÇAO:}

A avaliação do desempenho do funcionário será feita pela Enfermeira e entregue à Chefia do Serviço de Enfermagem.

Após 38 dias da sua admissão será avaliado. Se for satisfatório, terá o seu contrato de experiência prorrogado por mais 60 dias. No final desse período, novamente será avaliado. Sendo satisfatória a avaliação, será efetivado. A partir dá será submetido a avaliaçð̇es semestrais.

As cores para identificação de cada conceito, serão as seguintes:

VERDE - Otimo
AZUL $\quad$ Bom
VERMELHO - Regular
AMARELO - Fraco
ITENS A SEREM AVALIADOS:
I) Integridade Moral
II) Disciplina
III) Equilibrio emocional
IV) Liderança e Iniciativa
V) Saúde
VI) Qualidade do trabalho
VII) Facilidade para aprender
VIII) Aparência pessoal
IX) Hábitos de Segurança


Nome:

Data de Nasc.:........................ Estado Civil:

Benef.:

Residência :

C. Prof.:

Série:

RG.:

Data da Admissão:.......................... No Ponto:

Categoria Profissional:

Locação:

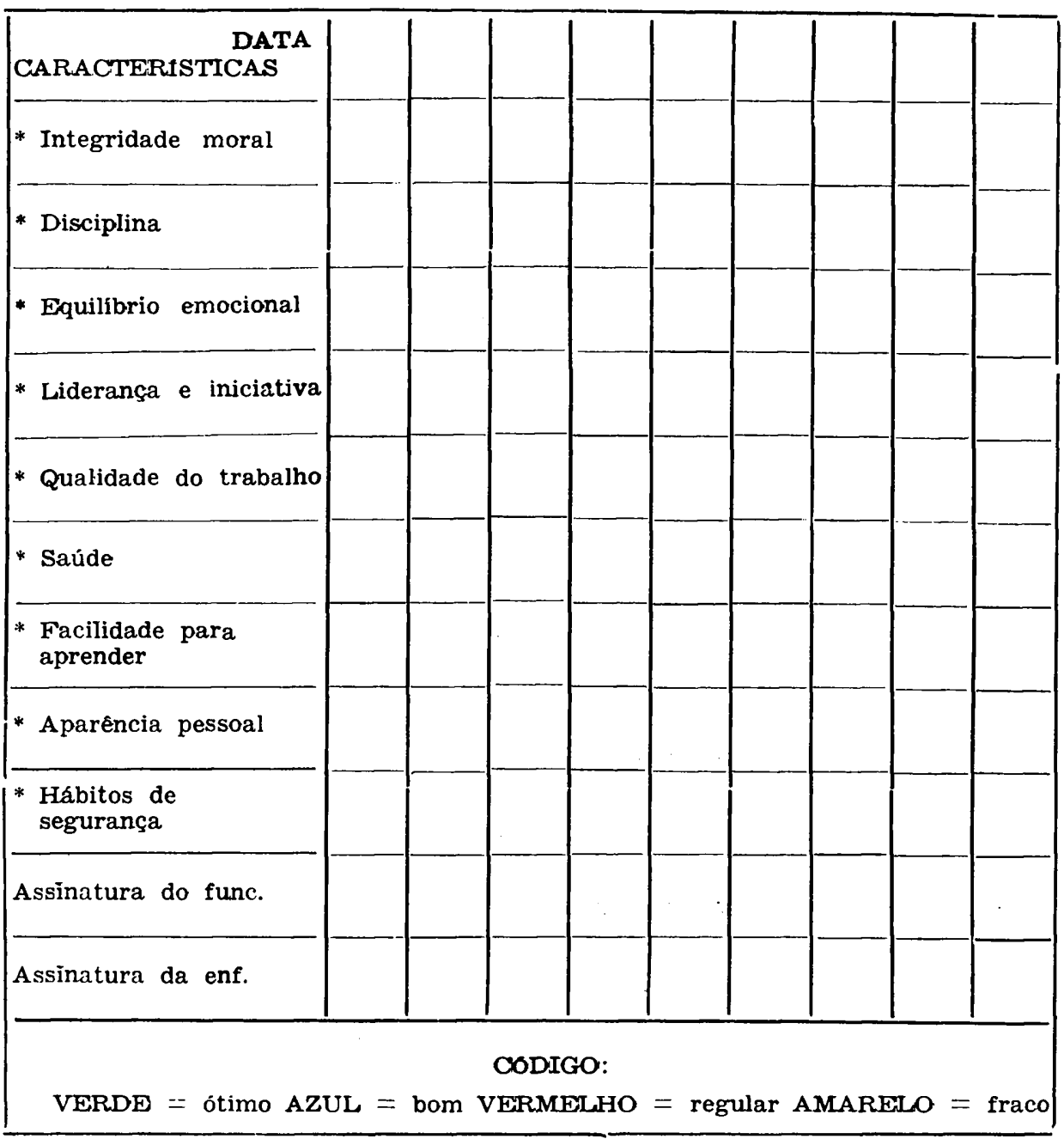




\section{ANEXO III}

BOLETIM DE AVALIAÇAO DE ENFERMAGEM - ENFERMEIRAS

Os critérios usados na avaliação conduzirão a uma análise da efíciéncia da avaliada, considerados os seguintes objetivos propostos:

I) Liderança e Participaçăo

II) Conhecimento e Atuaça

III) Perfil

\section{AVALTAÇAO}

I) Lderanga o Participaça (Peso 5)

1) Conhece a filosofia de trabalho da área de atuação

2) Dessenvolve as atividades dirigtdas para um objetivo comum

3) Estimula a participaçăo de colegas e subordinados

4) Identifica necessidades e as avalia, estabelece prioridades e planeja

5) Conhece sua posição dentro da estrutura institucional

6) Estabelece com facilidade a relação entre o sucesso assistencial e os recursos disponiveis (material e humano)

7) consciente das suas próprias limitaçöes

8) assíduo e pontual

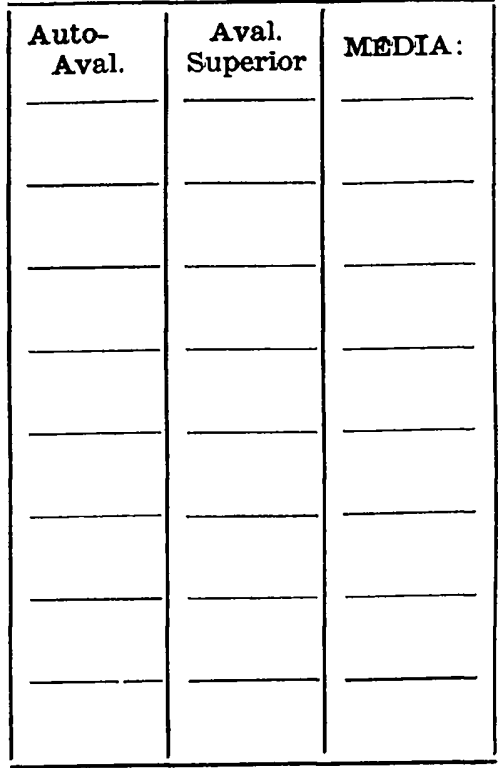

MEDTA:

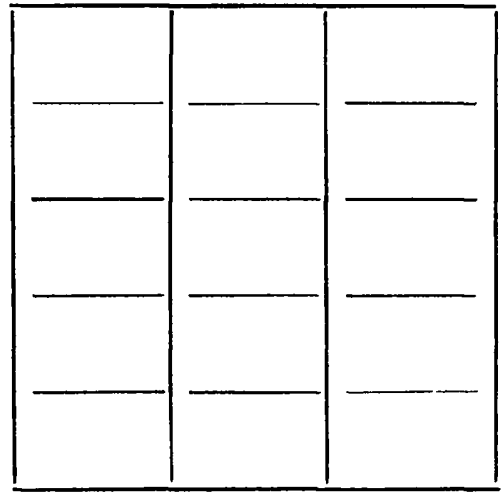

MEDIA: 
III) Perfll (Peso 1)
1) Simpático
2) Compreensivo
3) Persistente
4) Leal
5) Educado
6) Responsável

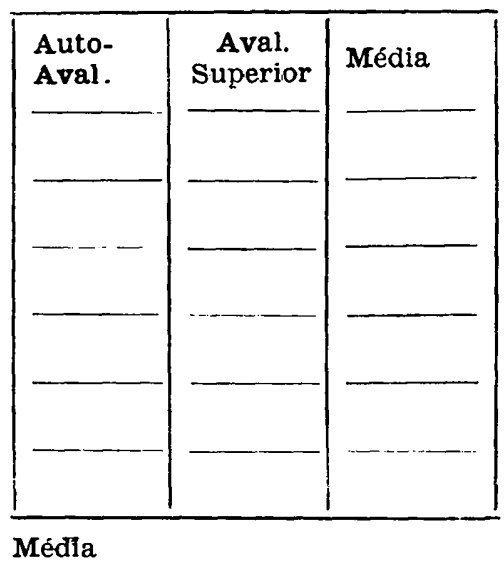

As notas atribuídas a cada um dos itens da ava!iação variam de 0 a 10.

* A média final ou global é uma média ponderada (fruto de notas atribuídas em auto-avaliação \& avaliação por parte da Chefia imediata ou do grupo de trabalho).

* Uma média fina l abaixo de 7 (sete) recomenda a não permanência do profissional em atividades no serviço.

As notas corresponderão aos seguintes conceitos:
Abaixo de 7,00
MAU (Amarelo)
De 7,00 a 7,99
REGULAR (Vervelho)
De 8,00 a 8,99
BOM (Azul)
De 9,00 a 10,0
OTIMO (Verde)

Avaliada :

Avaliador:

Data:

Recebido em 07/05/90 